\title{
Effects of microRNA-126 on cell proliferation, apoptosis and tumor angiogenesis via the down-regulating ERK signaling pathway by targeting EGFL7 in hepatocellular carcinoma
}

\author{
Cheng Gong ${ }^{1}$, Jing Fang ${ }^{2}$, Guang $\mathbf{L i}^{2}$, Han-Han Liu ${ }^{3}$ and Zhi-Su Liu ${ }^{1}$ \\ ${ }^{1}$ Department of General Surgery, Research Center of Digestive Diseases, Zhongnan Hospital of Wuhan University, Wuhan \\ 430071, P.R. China \\ ${ }^{2}$ Department of Oncology, Wuhan Pu-Ai Hospital, Tongji Medical College, Huazhong University of Science and Technology, \\ Wuhan 430034, P.R. China \\ ${ }^{3}$ Department of Pathology, Maternal and Child Health Hospital of Hubei Province, Wuhan 430070, P.R. China \\ Correspondence to: Han-Han Liu, email: hanhanl1010@163.com \\ Zhi-Su Liu, email: zsliu53@126.com
}

Keywords: microRNA-126, epidermal growth factor-like domain 7 (EGFL7), hepatocellular carcinoma, ERK signaling pathway, proliferation

Received: October 12, $2016 \quad$ Accepted: March 24, $2017 \quad$ Published: April 20, 2017

Copyright: Gong et al. This is an open-access article distributed under the terms of the Creative Commons Attribution License 3.0 (CC BY 3.0), which permits unrestricted use, distribution, and reproduction in any medium, provided the original author and source are credited.

\section{ABSTRACT}

This study intends to explore the effects of microRNA-126 (miR-126) on cell proliferation, apoptosis, and tumor angiogenesis in hepatocellular carcinoma (HCC) by regulating epidermal growth factor-like domain 7 (EGFL7) through extracellular signalregulated kinase (ERK) signaling. HCC tissues and adjacent normal tissues were obtained from 184 HCC patients. HCC cells were separately transfected with recombinant plasmids. Western blotting and qRT-PCR were applied to detect miR-126 and EGFL7, ERK, Fas/ FasL, Bcl-2, Caspase mRNA and protein levels. CCK8 and TUNEL were performed to determinate cell proliferation and apoptosis. Flow cytometry was used to analyze cell cycle distribution. Rats model of HCC was constructed, and tumor weight and the number of new blood vessels were recorded after 3 weeks of tumor transplantation. Compared with the adjacent normal tissues, HCC tissues exhibited lower miR-126 expression, and higher EGFL7, and ERK mRNA and protein levels. Overexpression of miR-126 in HCC cell lines suppressed EGFL7, ERK, BCl-2, and P-ERK, and increased apoptotic-associated proteins Fas/FasL and Caspase-3, and it inhibited cell proliferation and induced cell apoptosis. Overexpression of miR-126 in nude mice resulted in reduced tumor weight and less new blood vessels in tumors. The inhibition of miR-126 decreased cell apoptosis, and enhanced cell proliferation and tumor angiogenesis. This study demonstrates that miR126 might decrease cell proliferation, induce apoptosis, and inhibit tumor angiogenesis in HCC by inhibiting EGFL7 via down-regulating the ERK signaling pathway.

\section{INTRODUCTION}

Hepatocellular carcinoma (HCC) is the sixth most common cancer and the third leading cause of cancer mortality worldwide [1]. Each year, over 110, 000 deaths are estimated among patients suffering from HCC in China [2]. Although modern therapeutic strategies are relatively effective, HCC patients have an unsatisfactory prognosis owing to tumor metastasis and intrahepatic recurrence [3]. The morbidity and mortality of HCC are still increasing [4]. In spite of more comprehensive understanding of
HCC development and progression, it remains important to determine the molecular mechanisms in HCC in order to provide more effective targeted therapies. MicroRNAs (miRNAs) are a family of endogenously expressed, small non-coding RNAs which modulate gene expression by binding to the $3^{\prime}$ untranslated region (3'-UTR) of their target mRNAs, leading to repression or degradation of protein translation [5]. miRNAs functions in various physiological processes, including cell proliferation, differentiation, apoptosis, invasion, metastasis metabolism, and maturation. Their aberrant expression may modulate 
these pathological processes in human cancers through altered regulation of critical oncogenes or tumor suppressors $[6,7]$. The abnormal expressions of miRNAs have been presented in HCC to affect the development and progression [8-10].

miR-126 is dysregulated in many human cancers, modulating the proliferation, migration, and invasion of cancer cells in conjunction with various target genes [11-13]. miR-126 serves as a tumor suppressor, inhibiting cell proliferation and inducing cell apoptosis in HCC [14]. Saito et al. reported that miR-126 is situated within the gene for epidermal growth factor-like domain 7 (EGFL7), which is highly expressed in vascularized tissues and endothelial cells and acts as an important gene in angiogenesis [15]. Angiogenesis is dysregulated in chronic liver disease and plays a crucial role in the early stages of tumor development [16-18]. In addition, extracellular signal-regulated kinase (ERK) is reported to contribute to cell proliferation in HCC [4]. Our study aims to explore the potential mechanism of miR-126 affecting cell proliferation, apoptosis, and angiogenesis in $\mathrm{HCC}$ via mediating EGFL7 and the ERK signaling pathway.

\section{RESULTS}

\section{Correlation between clinicopathological characteristics and the prognosis of $\mathrm{HCC}$ patients}

One hundred eighty-four HCC patients including 156 males and 28 females, with a mean age of $48.97 \pm$ 9.33 years (aged from 23-72 years) were enrolled in our study. They had not received any treatment against primary tumors before surgery. They had no other complications or family disease history, and they received adjuvant threedimensional conformal radiation therapy (3DCRT) after surgery. According to tumor-node-metastasis (TNM) staging [19], there were 63 cases with stage I HCC, 12 cases with stage II HCC, 61 cases with stage III HCC, and 48 cases with stage IV HCC. There were 31 cases without liver cirrhosis, 46 cases with mild liver cirrhosis, 72 cases with moderate liver cirrhosis, and 35 cases with severe liver cirrhosis. Regarding the differentiation degree, there were 38 cases with grade I; 66 cases with grade II; 33 cases with grade III; and 47 cases with grade IV. During follow up, 68 cases died among the 184 patients. The correlation between clinicopathological characteristics and the prognosis of HCC patients is shown in Table 1.

\section{Transfection efficiency of recombinant plasmids in HepG2, Bet-7402, and smmc-7721 cells}

HepG2, Bet-7402, and smmc-7721 cells were transfected with recombinant plasmids (pLEGFPN1-miR-126 mimic, pLEGFP-N1-miR-126 inhibitor, pLEGFP-N1-miR-126 mimic NC, pLEGFP-N1-miR-126 inhibitor NC, or pLEGFP-N1-si EGFL7). The transfection efficiency up to $90 \%$ evaluated by flow cytometry indicated the successful transfection (Figure 1).

\section{miR-126 expression was negatively correlated with EGFL7 and ERK levels in HCC tissues and cell lines}

Compared with the adjacent normal tissues, the miR126 expression in HCC tissues was downregulated while EGFL 7 and ERK mRNA expressions were upregulated (all $P<0.05$ ), indicating low miR-126 expression and high EGFL 7 and ERK expressions might promote the risk of HCC. Among three HCC cell lines (HepG2, Bet-7402 and smmc-7721), the lowest miR-126 expression was observed in smmc-7721 cells, and the highest in HepG2 cells. Compared with the blank group, no significant difference was observed in the miR-126 expression and expressions of EGFL7, ERK, Fas/FasL, Bcl-2 and Caspase3 mRNAs in the miR-126 inhibitors + si-EGFL7, mimics control and inhibitors control groups (all $P>0.05$ ). In the miR-126 mimics group, the miR-126 expression and Fas/FasL and Caspase 3 mRNA expressions were significantly increased and the EGFL 7, ERK, and Bcl-2 mRNA expressions were notably decreased in comparison to the blank group (all $P>0.05)$. In the miR-126 inhibitors group, the miR-126 expression and Fas/FasL and Caspase 3 mRNA expressions were evidently downregulated while EGFL7, ERK, and Bcl-2 mRNA expressions were markedly upregulated when compared with the blank group (all $P<0.05$ ). These results showed that miR-126 expression was negatively correlated with EGFL 7 and ERK (Figures 2, 3).

\section{Inhibition of EGFL7 blocked the ERK signaling pathway to promote the apoptosis of $\mathrm{HCC}$ cells}

EGFL7, ERK, and P-ERK protein expressions in HCC tissues were significantly higher than these in the adjacent normal tissues (all $P<0.05$ ), indicating that increased EGFL7, ERK, and P-ERK expression may contribute to the risk of HCC (Figure 4). Among three HCC cell lines (HepG2, Bet-7402 and smmc-7721), the EGFL7 protein expression was highest in smmc-7721 cells, and lowest in HepG2 cells. Compared with the blank group, no significant difference was observed in the expressions of EGFL7, ERK, P-ERK, Bcl-2 Fas/FasL and Caspase 3 proteins in the miR-126 inhibitors + siEGFL7, mimics control, and inhibitors control groups (all $P>0.05)$. The miR-126 mimics group exhibited markedly higher Fas/FasL and Caspase3 protein expressions and lower EGFL7, ERK, P-ERK, and Bcl-2 protein expressions than the blank group (all $P>0.05$ ). Compared with the blank group, Fas/FasL and Caspase 3 protein expressions were decreased, and EGFL7, ERK, P-ERK, $\mathrm{Bcl}-2$ protein expressions were significantly increased in the miR-126 inhibitors group (all $P<0.05$ ), suggesting 


\begin{tabular}{|c|c|c|c|c|}
\hline \multirow{2}{*}{ Clinicopathological characteristic } & \multirow{2}{*}{ Total case } & \multirow{2}{*}{ Death } & \multicolumn{2}{|c|}{ Univariate analysis } \\
\hline & & & HR (95\%CI) & $\boldsymbol{P}$ \\
\hline \multicolumn{5}{|l|}{ Age (years) } \\
\hline$\leq 50$ & 103 & 36 & Ref. & \\
\hline$>50$ & 81 & 32 & $1.075(0.858-1.348)$ & 0.542 \\
\hline \multicolumn{5}{|l|}{ Gender } \\
\hline Male & 156 & 60 & Ref. & \\
\hline Female & 28 & 8 & $0.862(0.661-1.123)$ & 0.397 \\
\hline \multicolumn{5}{|l|}{ HBsAg } \\
\hline No & 23 & 6 & Ref. & \\
\hline Yes & 161 & 62 & $1.202(0.916-11.578)$ & 0.356 \\
\hline \multicolumn{5}{|l|}{ Tumor size (cm) } \\
\hline$\leq 5$ & 76 & 18 & Ref. & \\
\hline$>5$ & 108 & 50 & $1.421(1.146-1.763)$ & 0.002 \\
\hline \multicolumn{5}{|l|}{ Tumor number } \\
\hline Single & 123 & 15 & Ref. & \\
\hline Multiple & 61 & 53 & $6.695(3.497-12.82)$ & $<0.001$ \\
\hline \multicolumn{5}{|l|}{ TNM staging } \\
\hline Stage I-II & 75 & 17 & Ref. & \\
\hline Stage III-V & 109 & 51 & $1.453(1.173-1.801)$ & 0.001 \\
\hline \multicolumn{5}{|l|}{ Live cirrhosis degree } \\
\hline No and mild & 77 & 20 & Ref. & \\
\hline Moderate and severe & 107 & 48 & $1.343(1.082-1.666)$ & 0.013 \\
\hline \multicolumn{5}{|l|}{ Differentiation degree } \\
\hline Grade I-II & 104 & 52 & Ref. & \\
\hline Grade III-IV & 80 & 17 & $0.625(0.501-0.780)$ & $<0.001$ \\
\hline
\end{tabular}

Note: HCC, hepatocellular carcinoma; HR, Hazard Ratio; CI, confidence intervals.
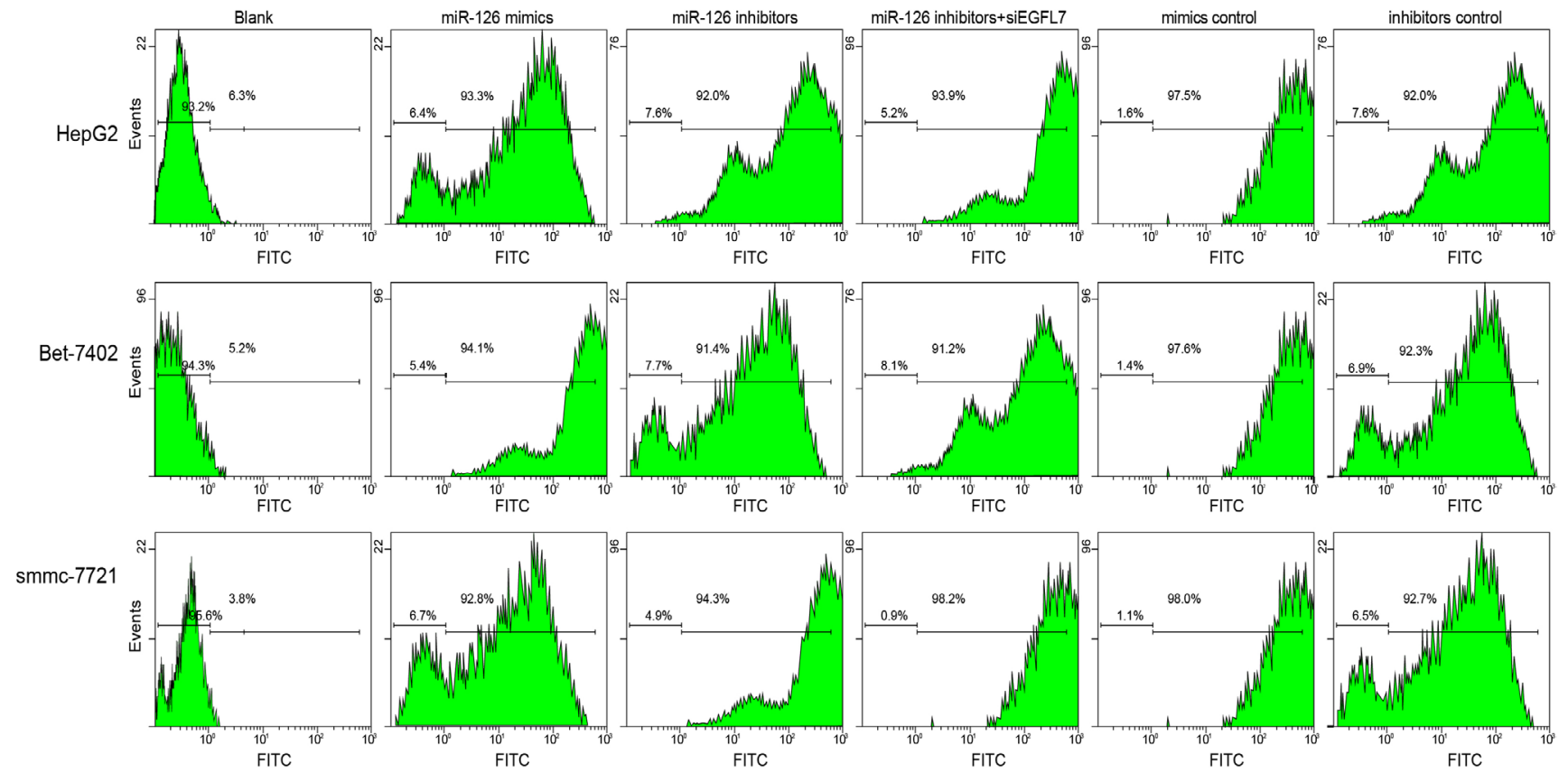

Figure 1: The transfection efficiency of recombinant plasmids pLEGFP-N1-miR-126 mimic, pLEGFP-N1-miR-126 inhibitor, pLEGFP-N1-miR-126 mimic NC, pLEGFP-N1-miR-126 inhibitor NC and pLEGFP-N1-si EGFL7 determined by flow cytometry. A. transfection efficiency of recombinant plasmids in HepG2 cells; B. transfection efficiency of recombinant plasmids in Bet-7402 cells; C. transfection efficiency of recombinant plasmids in smmc-7721 cells; miR-126, microRNA-126; EGFL7, epidermal growth factor-like domain 7; NC, negative control. 
that the low EGFL7 expression inhibited the activation of the ERK signaling pathway, promoting the expression of pro-apoptotic factors and HCC cell apoptosis [20].

\section{EGFL7: the direct target gene of miR-126}

The microRNA.org predicted that miR-126 was located in the introns 6 and 7 in the $3^{\prime}$-UTR of EGFL 7 and could bind to the 3'-UTR of EGFL7 mRNA. HepG2 cells were co-transfected with EGFL7-3'UTR-WT and miR-126 mimic plasmids. Compared with the EGFL7-3'UTR-WT + NC group (Figure 5), the ratio of Firefly luciferase activity to Renilla luciferase activity $(\mathrm{Y} / \mathrm{H})$ was significantly decreased in the EGFL7-3'UTR-WT + miR-126 mimic group $(P<$ $0.05)$, while no significant difference was observed between the EGFL7-3'UTR-MUT + miR-126 mimics and EGFL73 'UTR-WT + NC groups $(P>0.05)$. The results indicated that EGFL 7 was the direct target gene of miR-126.
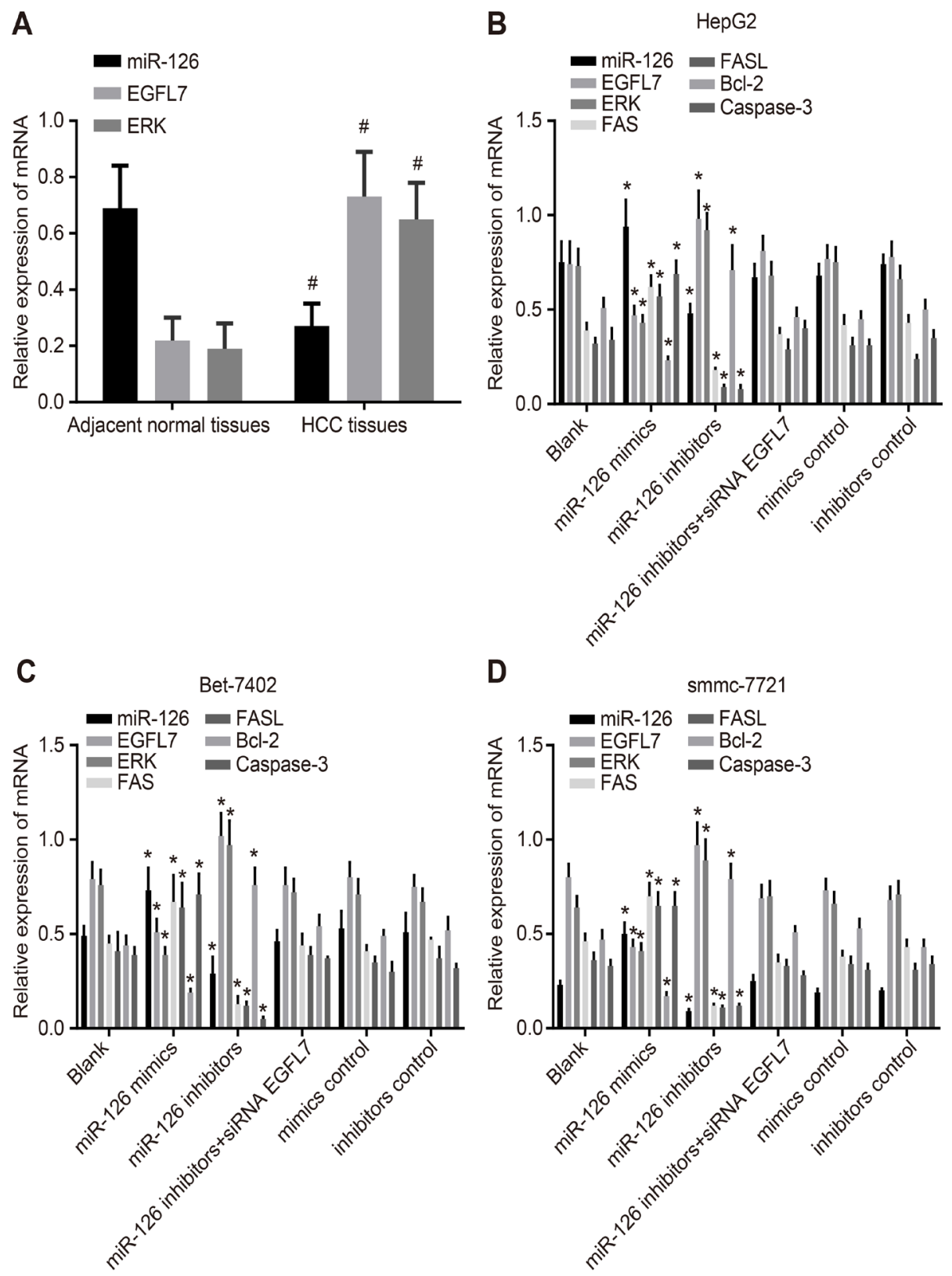

Figure 2: miR-126 expression and EGFL7, ERK, Fas/FasL, Bcl-2, and Caspase-3 mRNA expression in HCC tissues, adjacent normal tissues, and transfected HCC cell lines. (A). comparisons of miR-126 expression and EGFL7 and ERK mRNA expression between the HCC tissues and adjacent normal tissues; (B). comparisons of miR-126 expression and EGFL7, ERK, Fas/FasL, Bcl-2, and Caspase-3 mRNA expressions in HepG2 cells among the six groups; (C). comparison of miR-126 expression and EGFL7, ERK, Fas/FasL, Bcl-2, and Caspase-3 mRNA expressions in Bet-7402 cells among the six groups; (D). comparisons of miR-126 expression and EGFL7, ERK, Fas/FasL, Bcl-2 and Caspase-3 mRNA expressions in smmc-7721 cells among the six groups; ${ }^{*} P<0.05$ compared with adjacent normal tissues; $* P<0.05$ compared with the blank group; HCC, hepatocellular carcinoma; miR-126, microRNA-126; EGFL7, epidermal growth factor-like domain 7; ERK, extracellular signal-regulated kinase; FASL, FAS ligand; Bcl-2, B cell leukemia/lymphoma-2. 


\section{miR-126 overexpression suppressed the proliferation of $\mathrm{HCC}$ cells}

Shown as Figure 6, the proliferation of smmc-7721 cells was the highest, and that of HepG2 cells was the lowest among three HCC cell lines (HepG2, Bet-7402 and smmc-7721). No significant difference was observed in the proliferation of $\mathrm{HCC}$ cells in the miR-126 inhibitors + si-EGFL 7, mimics control and inhibitors control groups in comparison to the blank group (all $P>0.05$ ). Compared with the blank group, the proliferation of HCC cells in the miR-126 mimics group was decreased while that of HCC cells in the miR-126 inhibitors group was increased significantly (both $P<0.05$ ). These results indicated that miR-126 overexpression and inhibition of EGFL7 expression could suppress the proliferation of HCC cells. The proliferation of HCC cells might be enhanced when miR-126 expression was suppressed.

\section{miR-126 overexpression promoted the apoptosis of HCC cells}

After three HCC cell lines (smmc-7721, Bet-7402, and HepG2) were transfected with the recombinant plasmids, the apoptosis rate of $\mathrm{HCC}$ cells was significantly increased in the miR-126 mimics group and that of HCC cells was reduced in the miR-126 inhibitors group compared with the blank group, indicating that miR-126 overexpression could induce the apoptosis of HCC cells (Figure 7).

\section{miR-126 had no effect on cell cycle distribution of $\mathrm{HCC}$ cells}

Flow cytometry was used to detect cell cycle distribution in the three HCC cell lines (smmc-7721, Bet7402 and HepG2) after cell transfection (Table 2). No significant difference was observed in the ratios at $\mathrm{G} 0 / \mathrm{G} 1$ phase, G2/M phase, and S phase of smmc-7721, Bet-7402, and HepG2 cells among all six groups (all $P>0.05$ ).

\section{miR-126 overexpression reduced the proliferation of $\mathrm{HCC}$ cells in vivo}

The subcutaneous tumor volume in nude mice was gradually increased three days after transplantation. The tumor formation ability of smmc-7721 cells in the nude mice was the strongest, and that of HepG2 cells in the nude mice was the weakest among three HCC cell lines (HepG2,
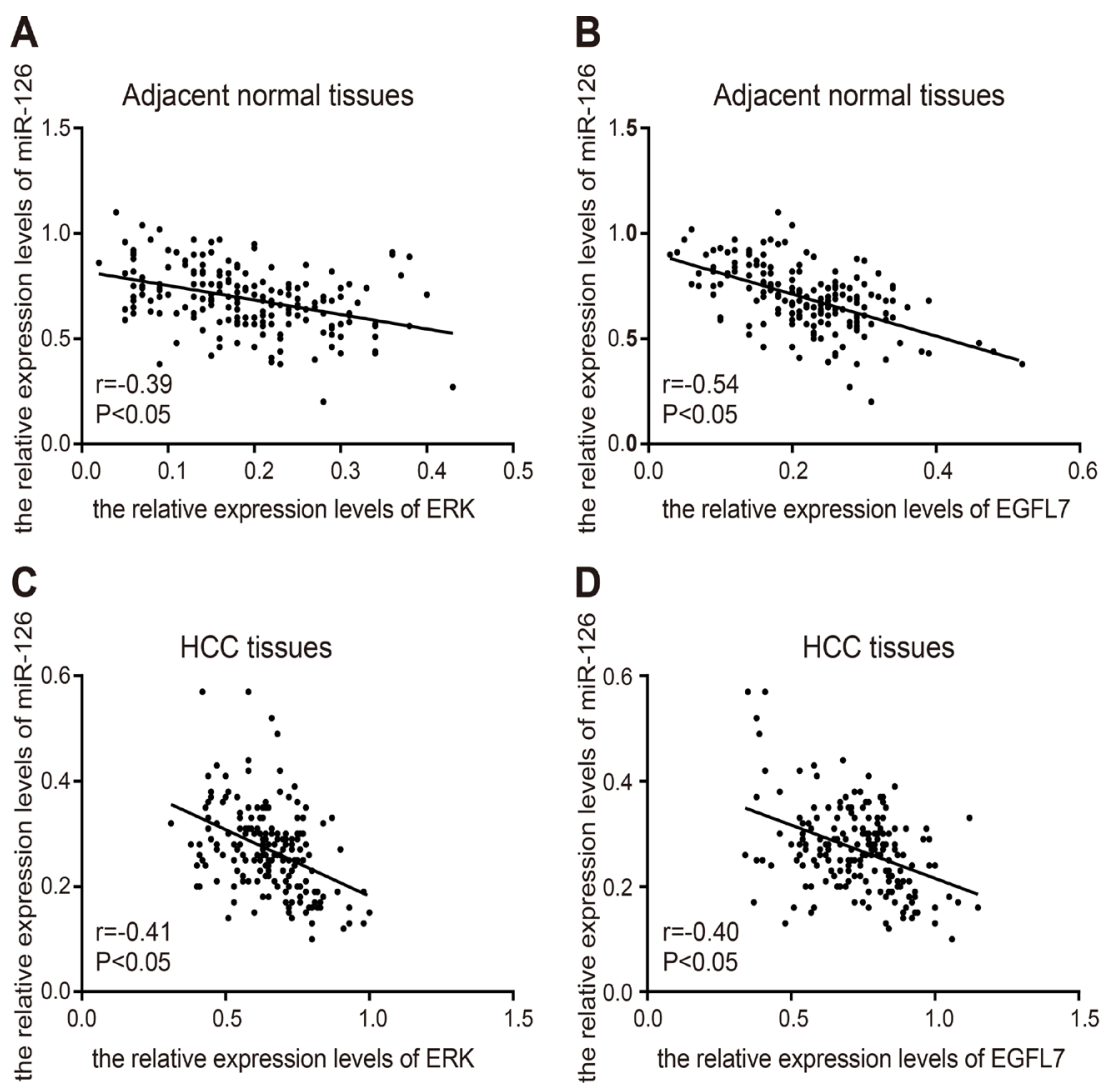

Figure 3: correlation analysis of miR-126, EGFL7, and ERK in HCC tissues and adjacent normal tissues. (A). correlation analysis of miR-126 and ERK in adjacent normal tissues; (B), correlation analysis of miR-126 and EGFL7 in adjacent normal tissues; (C), correlation analysis of miR-126 and ERK in HCC tissues; (D), correlation analysis of miR-126 and EGFL7 in HCC tissues. r, correlated coefficient; $r>0$, positive correlation; $r<0$, negative correlation; miR-126, microRNA-126; EGFL7, epidermal growth factor-like domain 7; ERK, extracellular signal-regulated kinase; HCC, hepatocellular carcinoma. 
Table 2: Cell cycle distribution in HepG2, Bet-7402 and smmc-7721 cells among the six groups

\begin{tabular}{|c|c|c|c|c|c|c|}
\hline Cell cycle & Blank group & $\begin{array}{c}\text { miR-126 } \\
\text { mimics } \\
\text { group }\end{array}$ & $\begin{array}{c}\text { miR-126 } \\
\text { inhibitors } \\
\text { group }\end{array}$ & $\begin{array}{l}\text { miR-126 inhibitors } \\
+ \text { si-EGFL7 group }\end{array}$ & $\begin{array}{l}\text { Mimics } \\
\text { control } \\
\text { group }\end{array}$ & $\begin{array}{l}\text { Inhibitors } \\
\text { control group }\end{array}$ \\
\hline \multicolumn{7}{|l|}{ HepG2 } \\
\hline G0/G1 phase & $56.81 \pm 0.23$ & $56.79 \pm 0.73$ & $57.06 \pm 0.92$ & $56.45 \pm 0.51$ & $57.17 \pm 0.33$ & $56.98 \pm 0.56$ \\
\hline G2/M phase & $12.73 \pm 0.31$ & $12.52 \pm 0.42$ & $12.96 \pm 0.27$ & $13.08 \pm 0.36$ & $12.87 \pm 0.39$ & $12.99 \pm 0.44$ \\
\hline S phase & $30.46 \pm 0.25$ & $30.69 \pm 0.77$ & $29.98 \pm 0.71$ & $30.47 \pm 0.78$ & $29.96 \pm 0.22$ & $30.03 \pm 0.99$ \\
\hline \multicolumn{7}{|l|}{ Bet-7402 } \\
\hline G0/G1 phase & $65.59 \pm 1.02$ & $64.62 \pm 0.58$ & $64.15 \pm 0.62$ & $64.30 \pm 0.87$ & $65.04 \pm 1.05$ & $64.27 \pm 0.83$ \\
\hline G2/M phase & $13.38 \pm 0.29$ & $14.27 \pm 0.31$ & $13.79 \pm 0.45$ & $13.63 \pm 0.38$ & $14.16 \pm 0.32$ & $13.99 \pm 0.12$ \\
\hline S phase & $21.03 \pm 0.82$ & $21.11 \pm 0.80$ & $22.06 \pm 0.19$ & $22.07 \pm 0.96$ & $20.80 \pm 0.73$ & $21.74 \pm 0.71$ \\
\hline \multicolumn{7}{|l|}{ smmc-7721 } \\
\hline G0/G1 phase & $73.17 \pm 0.62$ & $73.85 \pm 0.76$ & $73.21 \pm 0.59$ & $74.19 \pm 0.93$ & $73.73 \pm 0.61$ & $73.68 \pm 0.72$ \\
\hline G2/M phase & $7.57 \pm 0.33$ & $7.83 \pm 0.41$ & $7.67 \pm 0.28$ & $7.84 \pm 0.25$ & $8.07 \pm 0.36$ & $7.90 \pm 0.19$ \\
\hline S phase & $19.26 \pm 0.57$ & $18.32 \pm 0.36$ & $19.12 \pm 0.33$ & $17.97 \pm 1.15$ & $18.20 \pm 0.89$ & $18.42 \pm 0.76$ \\
\hline
\end{tabular}

Note: miR-126, microRNA-126; EGFL7, epidermal growth factor-like domain 7; si-EGFL7; siRNA EGFL7.

Bet-7402 and smmc-7721). The miR-126 inhibitors group exhibited the strongest tumor formation ability with faster tumor cell growth and the miR-126 mimics group had the weakest tumor formation ability with slower tumor cell growth among the six groups (Figure 8). The mice were sacrificed after three weeks, and no significant difference was observed in tumor volume and weight of the miR-126 inhibitors + si-EGFL7, mimics control and inhibitors control groups compared with the blank group (all $P>0.05$ ). The tumor weight in the miR-126 mimics group was decreased and the tumor weight in the miR-126 inhibitors group was evidently increased than that in the blank group (Table 3 ). Therefore, the miR-126 overexpression and inhibition of EGFL7 expression might suppress the proliferation ability of tumor cells in vivo. The proliferation ability of tumor cells might be enhanced by the inhibition of miR-126.

\section{miR-126 overexpression induced tumor angiogenesis of $\mathrm{HCC}$ cells in vivo}

The number of new blood vessels was the highest in the nude mice transplanted with smmc-7721 cells, and that was lowest in the nude mice transplanted with HepG2 cells among the three HCC cell lines which were transfected with recombinant plasmids (Table 3). No significant difference in the number of new blood vessels was observed among the blank, miR-126 inhibitors + siEGFL7, mimics control, and inhibitors control groups (all $P>0.05$ ). The miR-126 mimics group had markedly less new blood vessels and that in the miR-126 inhibitors group exhibited significantly more new blood vessels than the blank group (both $P<0.05$ ). Therefore, the miR-126 overexpression could inhibit tumor angiogenesis.

\section{miR-126 overexpression inhibited expressions of EGFL7, ERK, P-ERK, angiogenesis-associated proteins VEGF, and CD31 in HCC cells in vivo}

The EGFL7 expression was the highest in smmc7721 cells in vivo, and lowest in HepG2 cells among three HCC cells lines which was transfected with recombinant plasmids (Figure 9). No significant difference was observed in EGFL7, ERK, P-ERK, VEGF, and CD31 protein expressions among the blank, miR-126 inhibitors + si-EGFL7, mimics control and inhibitors control groups (all $P>0.05$ ). EGFL7, ERK, P-ERK, VEGF, and CD31 protein expressions were decreased in the miR-126 mimics group, but these were significantly elevated in the miR-126 inhibitors group relative to the blank group (all $P<0.05$ ). These results showed that miR-126 overexpression could reduce the expression of ERK, P-ERK and angiogenesisassociated proteins, inhibiting tumor angiogenesis and tumor growth.

\section{DISCUSSION}

In this study, we showed that miR-126 was significantly reduced in HCC tissues, and the elevation of miR-126 could decrease cell proliferation, induce cell apoptosis, and inhibit angiogenesis in HCC cells. Further experiments indicated that the function of miR-126 in HCC is achieved by targeting EGFL7 and subsequently regulating of the ERK signaling pathway.

Our initial results revealed that miR-126 is significantly downregulated, while the mRNA and protein expression of EGFL7 and ERK are upregulated in HCC tissues. MiR-126 expression is downregulated in human 
cancers, reducing its ability to suppress the proliferative and invasive capacities of cancer cells, such as lung cancer, osteosarcoma, oral cancer and so on $[11,12,21]$. Wong et al. have found that miR-126 is significantly decreased in patients carrying hepatitis B and C virus, and lower miR-126 expression predicts poor survival and tumor recurrence for HCC patients after surgery [22]. Also, EGFL7 is elevated in HCC patients, which functions as a chemoattractant for cell migration [23]. MiR-126 overexpression using miR-126 mimics could significantly reduce the phosphorylation of ERK protein [24]. Additionally, our study has indicated that EGFL7 is the target gene of miR-126. MiR-126 is situated in an intron of EGFL 7, and miR-126 could be generated by 3 different transcripts on EGFL 7 [15]. A mechanism of miR126 targeting EGFL 7 to inhibit cell proliferation has also been confirmed by Sun et al. in non-small cell lung cancer

A

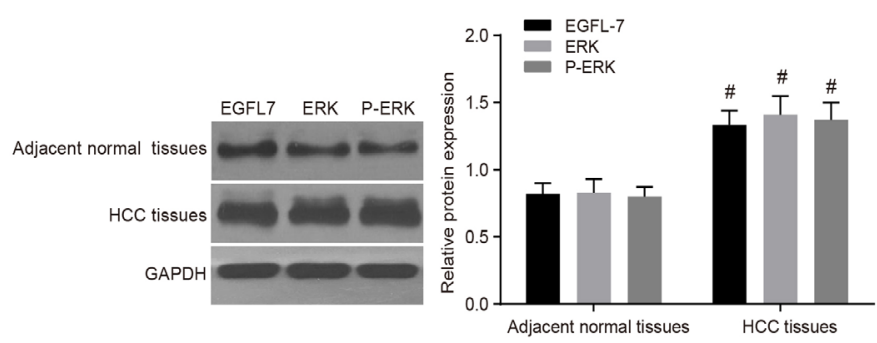

C
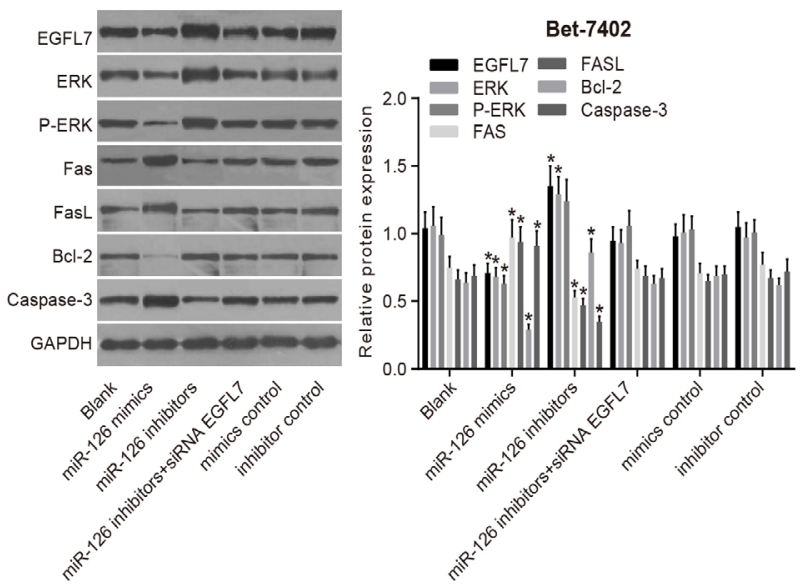

[25]. Moreover, miR-126 could reduce cell proliferation and tumor angiogenesis of HCC via decreasing EGFL7 expression [26], which is similar to our results, but the negative regulation of miR-126 on ERK signaling pathway was not involved.

Our study also demonstrates that overexpressed miR-126 decreases cell proliferation and induces cell apoptosis in HCC cells. We found that ERK and Bcl2 mRNA and protein levels are significantly reduced in the miR-126 mimics group, while those of Fas/ FasL and Caspase-3 are increased. Furthermore, the cell proliferation ability in vivo was reduced, while cell apoptosis was enhanced. The levels of ERK and Bcl-2 mRNA and protein were elevated in the miR-126 inhibitors group, while those of Fas/FasL and Caspase-3 were reduced. Importantly, Fas/FasL, Caspase-3 and Bcl-2 are considered as apoptosis-related genes [27]. The ERK

B
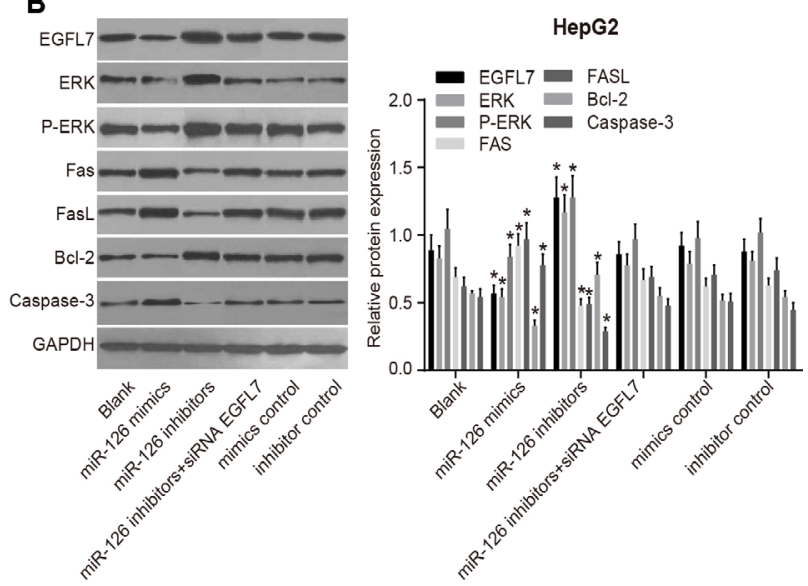

D
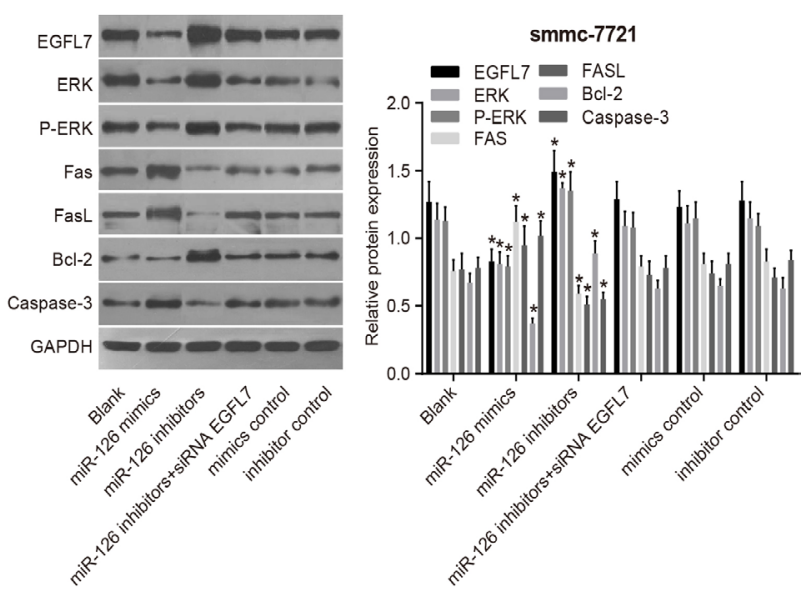

Figure 4: EGFL7, ERK, P-ERK, Fas/FasL, Bcl-2 and Caspase-3 protein expressions in HCC tissues, adjacent normal tissues and transfected HCC cell lines. (A). comparisons of the expressions of EGFL7, ERK, P-ERK, Fas/FasL, Bcl-2 and Caspase-3 proteins between the HCC tissues and adjacent normal tissues; (B). comparisons of the expressions of EGFL7, ERK, P-ERK, Fas/FasL, Bcl-2 and Caspase-3 proteins in HepG2 cells among the six group; (C). comparisons of the expressions of EGFL7, ERK, P-ERK, Fas/FasL, Bcl-2 and Caspase-3 proteins in Bet-7402 cells among the six group; (D). comparisons of the expressions of EGFL7, ERK, P-ERK, Fas/ FasL, Bcl-2 and Caspase-3 proteins in smmc-7721 cells among the six group; ${ }^{*} P<0.05$ compared with adjacent normal tissues; ${ }^{*} P<0.05$ compared with the blank group; HCC, hepatocellular carcinoma; miR-126, microRNA-126; EGFL7, epidermal growth factor-like domain 7; ERK, extracellular signal-regulated kinase. 
Table 3: Comparisons of the number of new vessels and tumor weight among the six grouos after tumor transplantation

\begin{tabular}{lcccccc}
\hline & Blank group & $\begin{array}{c}\text { miR-126 } \\
\text { mimics group }\end{array}$ & $\begin{array}{c}\text { miR-126 } \\
\text { inhibitors group }\end{array}$ & $\begin{array}{c}\text { miR-126 inhibitors }+ \\
\text { si-EGFL7 group }\end{array}$ & $\begin{array}{c}\text { Mimics control } \\
\text { group }\end{array}$ & $\begin{array}{c}\text { Inhibitors } \\
\text { control group }\end{array}$ \\
\hline HepG2 & & & & & \\
New vessels & $21.13 \pm 1.36$ & $9.63 \pm 3.02^{*}$ & $32.88 \pm 3.60^{*}$ & $22.88 \pm 3.56$ & $20.50 \pm 2.62$ & $19.25 \pm 2.12$ \\
$\begin{array}{l}\text { Tumor weight } \\
\text { Bet-7402 }\end{array}$ & $2.41 \pm 0.23$ & $1.04 \pm 0.19^{*}$ & $3.58 \pm 0.34^{*}$ & $2.37 \pm 0.21$ & $2.46 \pm 0.12$ & $2.39 \pm 0.14$ \\
New vessels & $28.63 \pm 2.72$ & $12.88 \pm 2.30^{*}$ & $39.00 \pm 4.90^{*}$ & $26.00 \pm 1.85$ & $30.00 \pm 4.21$ & $28.88 \pm 3.00$ \\
Tumor weight & $2.54 \pm 0.15$ & $1.23 \pm 0.16^{*}$ & $3.77 \pm 0.31^{*}$ & $2.42 \pm 0.22$ & $2.51 \pm 0.27$ & $2.46 \pm 0.30$ \\
smmc-7721 & & & & & $38.13 \pm 4.12$ & $33.88 \pm 1.96$ \\
New vessels & $35.88 \pm 3.98$ & $17.00 \pm 2.78^{*}$ & $48.00 \pm 4.93^{*}$ & $34.88 \pm 3.04$ & 38.12 \\
Tumor weight & $2.76 \pm 0.24$ & $1.56 \pm 0.19^{*}$ & $3.88 \pm 0.38^{*}$ & $2.55 \pm 0.23$ & $2.68 \pm 0.24$ & $2.57 \pm 0.27$ \\
\hline
\end{tabular}

Note: miR-126, microRNA-126; EGFL7, epidermal growth factor-like domain 7; si-EGFL7; siRNA EGFL7; ${ }^{*} P<0.05$ compared with the blank group.

signaling pathway is largely involved in cell proliferation and apoptosis in HCC [28-30]. Especially, the inactivation of the ERK signaling pathway could contribute to cell proliferation and induce cell apoptosis in HCC [28]. Zhao et al. have also demonstrated that the high miR-126 expression can inhibit cell proliferation, arrest cell cycle progress, and induce apoptosis in HCC cells [14], which is consistent with our study.
Moreover, overexpression of miR-126 inhibits angiogenesis triggered by the HCC cells. EGFL7, ERK, VEGF, and CD31 protein levels are reduced in the miR-126 mimics group, while EGFL7, ERK, P-ERK, VEGF, and CD31 protein are increased in the miR-126 inhibitors group. Angiogenesis is an important event in HCC progression, in which several angiogenic factors are commonly involved including VEGF and EGFL7 [31]. EGFL7 could enhance

A

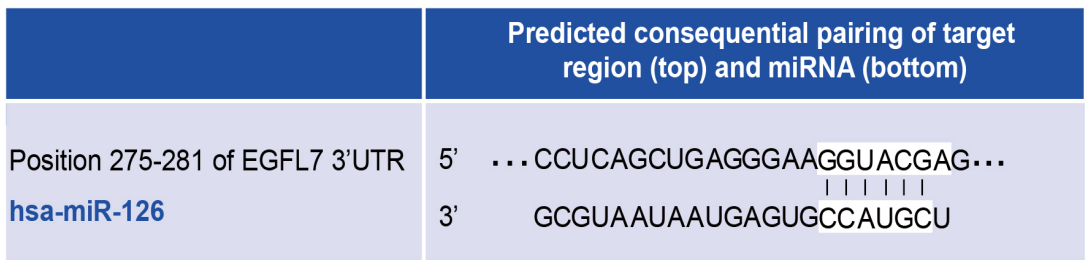

B

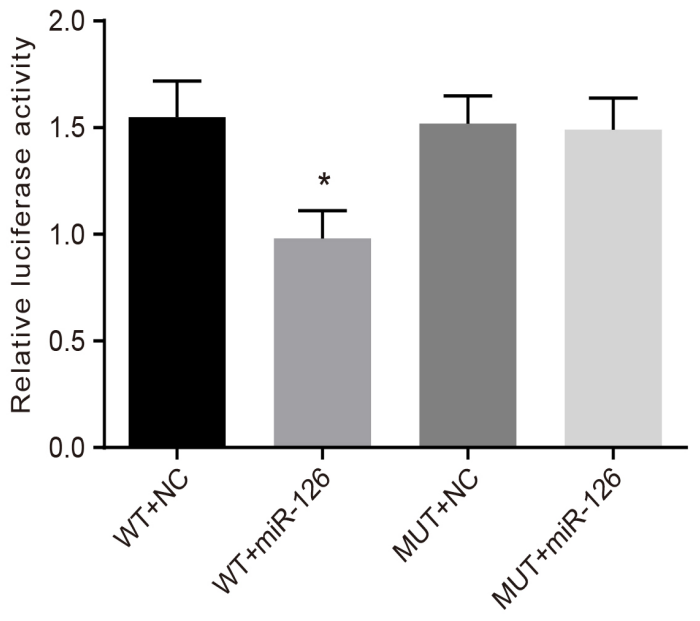

Figure 5: Identification of miR-126 targeting EGFL7. (A). the binding site of miR-126 and EGFL7 in the 3'UTR; (B). the luciferase activity at $48 \mathrm{~h}$ after the HepG2 cells were transfected with EGFL7-3'UTR-WT + NC, EGFL7-3'UTR-WT + miR-126, EGFL7$3^{\prime}$ UTR-MUT + NC and EGFL7-3'UTR-MUT + miR-126; ${ }^{*} P<0.05$ compared with cells transfected with EGFL7-3'UTR-WT + NC, EGFL7-3'UTR-MUT + NC or EGFL7-3'UTR-MUT + miR-126; miR-126, microRNA-126; EGFL7, epidermal growth factor-like domain 7; NC, negative control; 3'UTR, 3' untranslated region; WT, wide type; MUT, mutant type. 
HCC metastasis and invasion by improving cell motility via the phosphorylation of focal adhesion kinase (FAK) [32]. Interestingly, EGFL 7 is also reported to involve in blood vessel formation in human tumors, presenting an increase in highly vascularized tissues [25]. The blockage of ERK signaling inhibits angiogenesis in $\mathrm{HCC}$ with inactivated ERK1/2 phosphorylation [33]. CD31 participates in blood vessel formation during pathological processes, and CD31 expression often predicts acute and chronic angiogenesis [34]. Additionally, De Giorgio et al. have reported the loss of miR-126 may enhance angiogenesis through target specific proangiogenic factors at the in situ to invasive tumor transition, which could further prove our results [35].

To conclude, our study shows that miR-126 is downregulated in HCC tissues and that elevated miR-126 decreases proliferation and induces apoptosis in the HCC cells and inhibits angiogenesis. The effects of miR-126 on HCC cells may be achieved by targeting EGFL 7 and down-regulating the ERK signaling pathway. However, the full understanding of miR-126 with ERK signaling in HCC is still uncertain, and more researches are still required to identify and effective targeted treatment for HCC.

\section{MATERIALS AND METHODS}

\section{Ethical statement}

The study was conducted in accordance with approval of the Ethics Committee of Maternal and Child Health
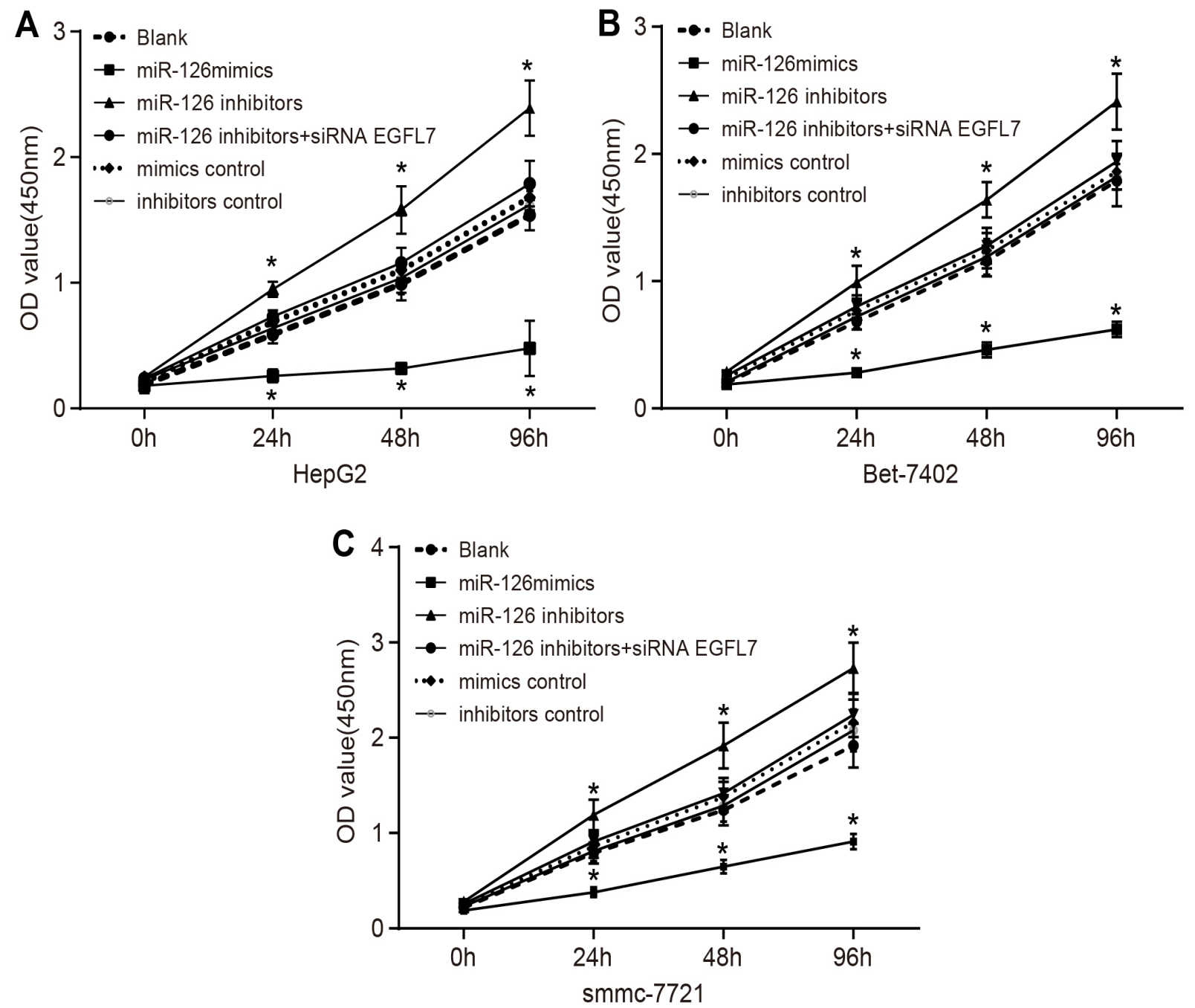

Figure 6: Comparison of cell proliferation among the blank, miR-126 mimics, miR-126 inhibitors, miR-126 inhibitors + siRNA EGFL7, mimics control, and inhibitors control groups after transfection. (A). the proliferation of HepG2 cells among the blank, miR-126 mimics, miR-126 inhibitors, miR-126 inhibitors + siRNA EGFL7, mimics control and inhibitors control groups after transfection; (B). the proliferation of Bet-7402 cells among the blank, miR-126 mimics, miR-126 inhibitors, miR-126 inhibitors + siRNA EGFL7, mimics control and inhibitors control groups after transfection; (C). the proliferation of smmc-7721 cells among the blank, miR-126 mimics, miR-126 inhibitors, miR-126 inhibitors + siRNA EGFL7, mimics control and inhibitors control groups after transfection; $* P<0.05$ compared with the blank group; miR-126, microRNA-126; EGFL7, epidermal growth factor-like domain 7. 
Hospital of Hubei Province. Written informed consent was collected from each eligible patient prior to the experiment.

\section{Study subjects}

A total of 184 patients with primary HCC who received treatment in Maternal and Child Health Hospital of Hubei Province between September 2010 and December 2013 were selected for this study. After surgery, $\mathrm{HCC}$ tissues and adjacent normal tissues were collected from all $\mathrm{HCC}$ patients, and clinicopathological data of enrolled patients were recorded. Human HCC cell lines (HepG2, Bet-7402, and smmc-7721) were purchased from the Cell Bank of Chinese Academy of Sciences (Shanghai, China). A total of 144 female nude mice (Department of Laboratory Animals, China Medical University, Shenyang, Liaoning, China) aged 3 months weighting $22 \pm 4 \mathrm{~g}$ were selected for the study. All animal experiments in our study were in accordance with the principles of the local Laboratory Animal Care and Use, and guidelines established by the US National Institutes of Health.

\section{Cell culture}

Cryopreserved HepG2, Bet-7402, and smmc7721 cells were thawed in a $38^{\circ} \mathrm{C}$ water bath and then centrifuged at $1000 \mathrm{rpm}$ for $5 \mathrm{~min}$. The supernatant was discarded and the cells were cultured in Dulbecco's Modified Eagle Medium (DMEM) medium in an incubator containing $5 \% \mathrm{CO}_{2}$ at $37^{\circ} \mathrm{C}$. The medium was replaced when cells adhered to the bottle wall. And the cells were subcultured till the cells covered $80 \%$ of the bottle bottom.

\section{Plasmid construction}

The siRNA plasmid of EGFL7 gene (si-EGFL7) was designed based on the EGFL7 coding sequence (NP_57299) using RNAi design software (Invitrogen Inc., Carlsbad, CA, USA) (Table 4). Human mature miR-126 mimics, miR-126 inhibitors, miR-126 mimics control, and miR-126 inhibitors control were purchased from Biomics Biotechnologies Co. Ltd (Nantong, Jiangsu, China). The oligonucleotide sequences of these plasmids were synthesized with Eco RI and Bam HI endonuclease cleavage sites inserted at the two ends of sequences, and then the DNA fragment was cloned into the pLEGFP-N1 vector. Therefore, the corresponding recombinant plasmids including pLEGFP-N1-miR-126 mimic, pLEGFP-N1miR-126 inhibitor, pLEGFP-N1-miR-126 mimic negative control (NC), pLEGFP-N1-miR-126 inhibitor NC, and pLEGFP-N1-si EGFL7. The fragment of EGFL7 gene containing miR-126 binding sites in $3^{\prime}$-UTR region was inserted into dual-luciferase reporter vector to construct recombinant wild-type plasmid (EGFL7-3'UTR-WT) and

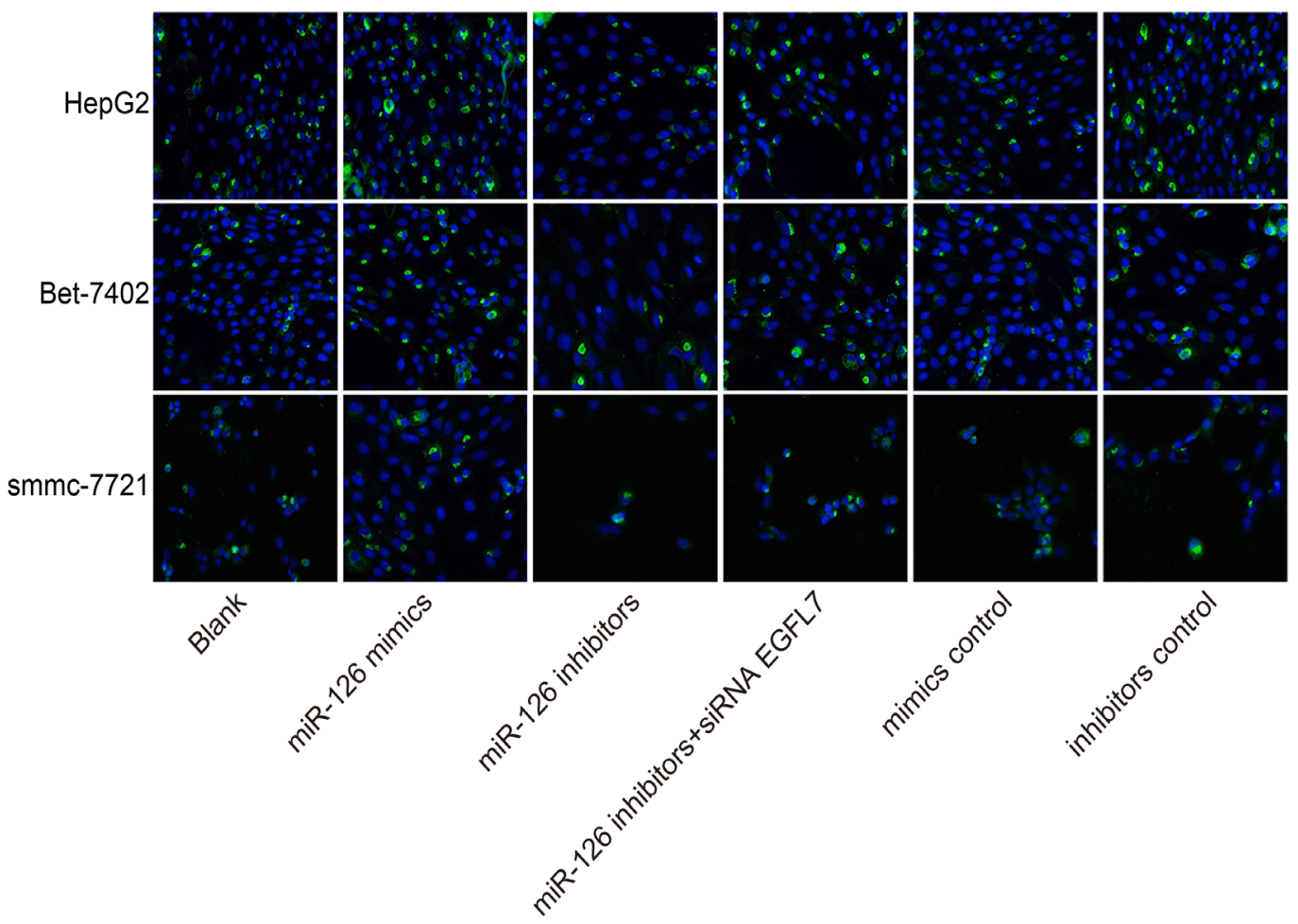

Figure 7: Comparisons of cell apoptosis among the blank, miR-126 mimics, miR-126 inhibitors, miR-126 inhibitors + siRNA EGFL7, mimics control and inhibitors control groups in smmc-7721, Bet-7402, and HepG2 cell lines after transfection $(\times \mathbf{4 0 0})$. Note: DAPI dye cell nucleus was blue; miR-126, microRNA-126; EGFL7, epidermal growth factor-like domain 7; DAPI, 4'-6-diamidino-2-phenylindole. 
Table 4: Oligonucleotides sequences of si-EGFL 7 and NC

\begin{tabular}{cl}
\hline Gene & Sequence \\
\hline $\boldsymbol{s i}$ - $\boldsymbol{G} \boldsymbol{F \boldsymbol { L } \text { 7 }}$ & 5'-AGCAGATTTCCTTCCTGGA-3' \\
$\mathrm{NC}$ & 5'-UUCUCCGAACGUGUCACGUTT-3' \\
\hline
\end{tabular}

Note: NC, negative control.

mutant-type plasmid (EGFL7-3'UTR-MUT). All plasmids were verified by polymerase chain reaction (PCR), restriction enzyme digestion, and DNA sequencing.

\section{Cell transfection}

HepG2, Bet-7402, and smmc-7721 cells in logarithmic phase were seeded into 96 -well plates $(100 \mu \mathrm{L} /$ well). And then these three cell lines were separately transfected with recombinant plasmids (pLEGFP-N1miR-126 mimic, pLEGFP-N1-miR-126 inhibitor, pLEGFPN1-miR-126 mimic NC, pLEGFP-N1-miR-126 inhibitor NC or pLEGFP-N1-si EGFL7) using Lipofectamine 2000 and then incubated in an incubator containing 5\% $\mathrm{CO}_{2}$ at $37^{\circ} \mathrm{C}$ for $6 \mathrm{~h}$. Next, cells were cultured with fresh medium containing 10\% fetal bovine serum (FBS) for $48 \mathrm{~h}$. Subsequently, cells were collected and washed with phosphate buffered saline (PBS) 3 times. After being fixed
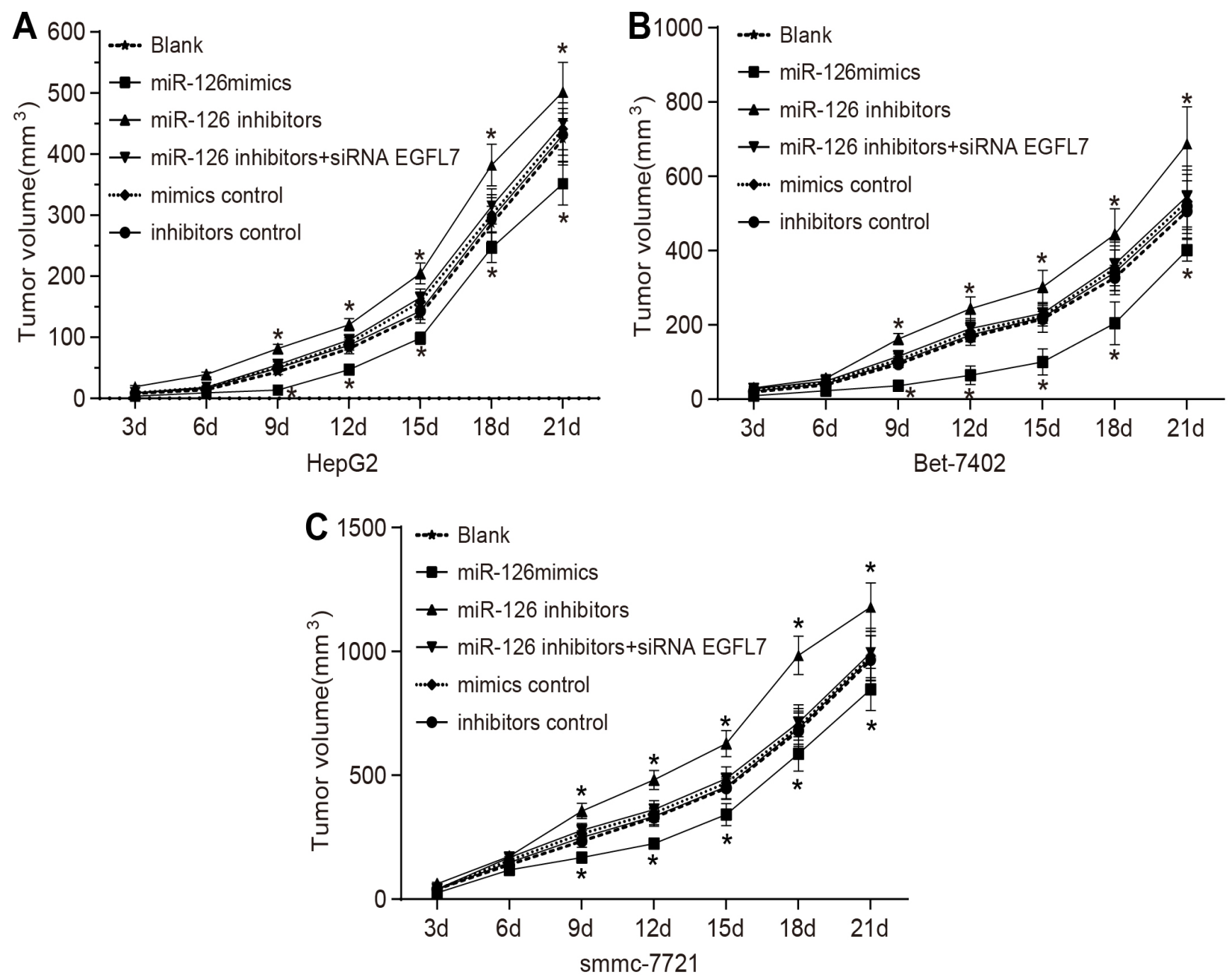

Figure 8: Tumor growth curves of nude mice transplanted with smmc-7721, Bet-7402 and HepG2 cell lines in the blank, miR-126 mimics, miR-126 inhibitors, miR-126 inhibitors + siRNA EGFL7, mimics control and inhibitors control groups. (A). tumor growth curves of mice transplanted with HepG2 cells in each group; (B). tumor growth curves of mice transplanted with Bet-7402 cells in each group; (C) tumor growth curves of mice transplanted with smmc-7721 cells for each group; $* P$ 0.05 compared with the blank group; miR-126, microRNA-126; EGFL7, epidermal growth factor-like domain 7. 
in $70 \%$ ice-cold ethanol at $-20^{\circ} \mathrm{C}$ for $30 \mathrm{~min}$, cells were incubated for $10 \mathrm{~min}$ with the addition of triton-x-100, followed by PBS washing for 3 times. The cells were resuspended in $100 \mu \mathrm{L}$ PBS, after which the transfection efficiency was identified by flow cytometry. The target gene of miR-126 was identified with dual-luciferase reporter assay. HEPG2 cells in logarithmic phase were seeded into 96-well plates, and co-transfected with EGFL7-3'UTR-WT and miR-126 mimic plasmids (EGFL7-3'UTR-WT + miR126) using Lipofectamine 2000 when the cell density was about 70\%. Meanwhile, cells co-transfected with EGFL73'UTR-WT and NC plasmids (EGFL7-3'UTR-WT + NC) and with EGFL7-3'UTR-MUT and miR-126 mimic plasmids (EGFL7-3'UTR-MUT + miR-126) as controls.
Chemiluminescence was used to detect the luciferase activity after 48-h culture in an incubator.

\section{Establishment of HCC nude mice model and grouping}

Three transfected cell lines (HepG2, Bet-7402 and smmc-7721) were separately divided into the blank group (without transfection), the miR-126 mimics group (transfected with miR-126 mimics plasmid), the miR-126 inhibitors group (transfected with miR126 inhibitors plasmid), the miR-126 inhibitors + siEGFL 7 group (transfected with miR-126 inhibitors + siEGFL7 plasmid), the mimics control group (transfected
A

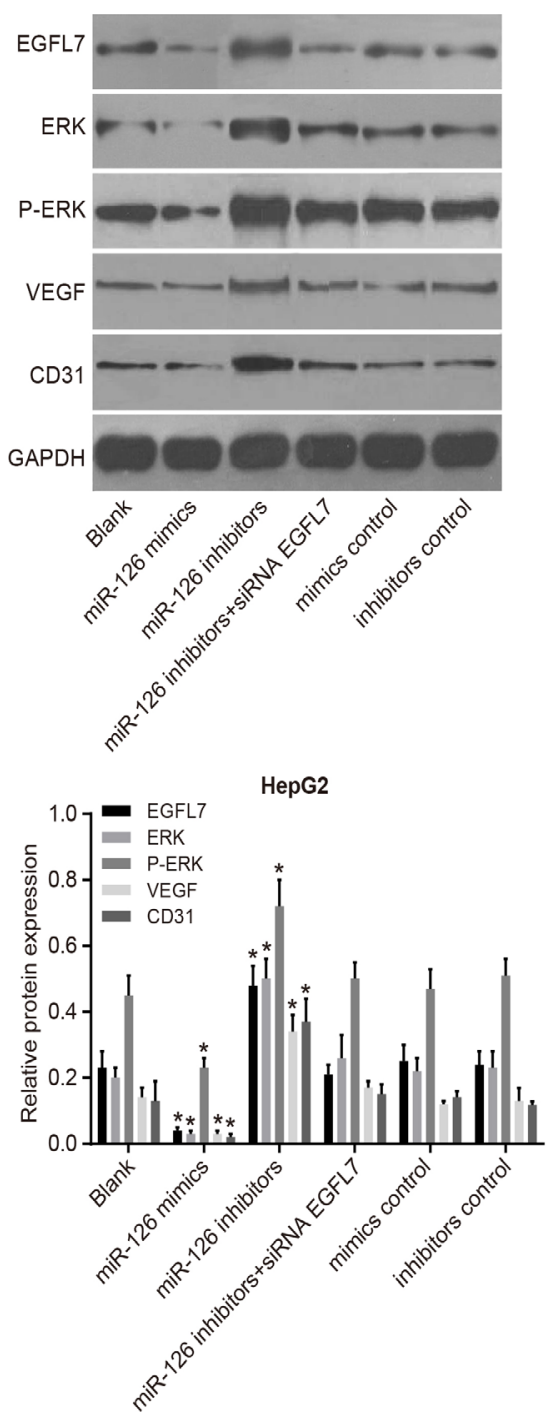

B

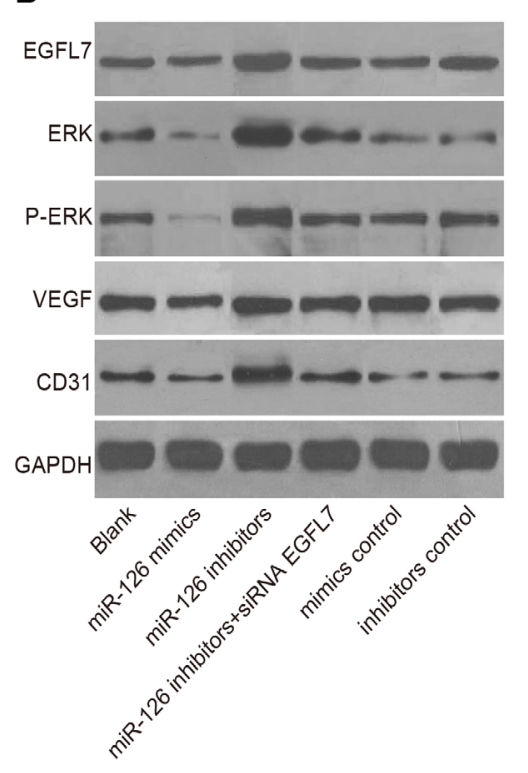

Bet-7402

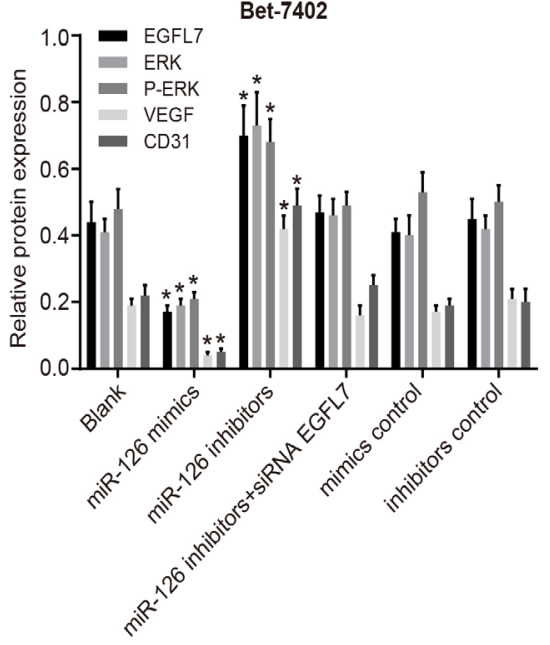

C
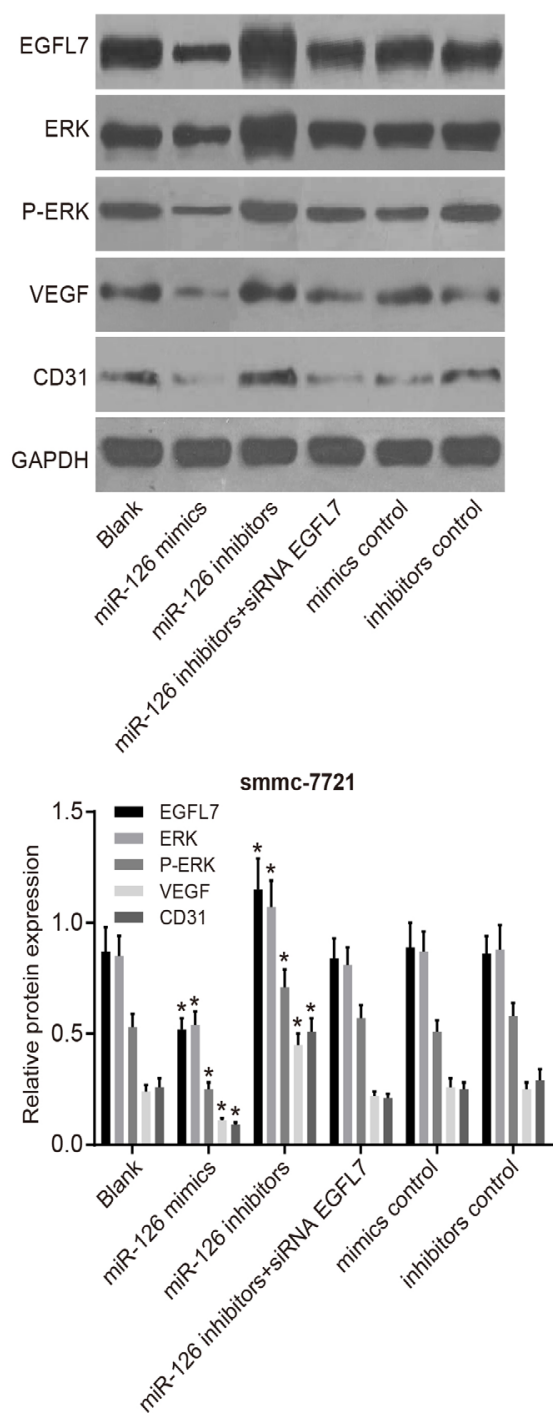

Figure 9: EGFL7, ERK, P-ERK, VEGF, and CD31 protein expressions in smmc-7721, Bet-7402 and HepG2 cell lines in vivo. (A). EGFL7, ERK, P-ERK, VEGF, and CD31 protein expression in HepG2 cells in vivo; (B). EGFL7, ERK, P-ERK, VEGF, and CD31 protein expression in Bet-7402 cells in vivo; (C). EGFL7, ERK, P-ERK, VEGF and CD31 protein expression in smmc-7721 cells in vivo; ${ }^{*} P<0.05$ compared with the blank group; miR-126, microRNA-126; EGFL7, epidermal growth factor-like domain 7; ERK, extracellular signal-regulated kinase; P-ERK, phosphorylated ERK; VEGF, vascular endothelial growth factor. 
with miR-126 mimics NC plasmid), and the inhibitors control group (transfected with miR-126 inhibitors NC plasmid). Transfected cells were collected and adjusted to a density of $1 \times 10^{6} / \mathrm{mL}$. The 12 -week-old nude mice were subcutaneously injected with $1 \mathrm{~mL}$ of transfected HCC cells (HepG2, Bet-7402, smmc-7721) into the back of the upper limbs to ensure the comparability of results. Rats injected with the same cell line were assigned into six groups ( 8 mice in each group): the blank group (injection of cells without transfected plasmids); the miR126 mimics group (injection of cells being transfected with miR-126 mimics plasmid); the miR-126 inhibitors group (injection of cells being transfected with miR-126 inhibitors plasmid); the miR-126 inhibitors + siRNA EGFL 7 group (injection of cells being transfected with miR-126 inhibitors + siRNA EGFL7 plasmids); the mimics control group (injection of cells being transfected with miR-126 mimics NC plasmid); and the inhibitors control group (injection of cells being transfected with miR-126 inhibitors NC plasmid). The mice were fed in a specific pathogen-free (SPF) environment after tumor implantation, and the tumor formation in nude mice was observed. The long diameter (a) and short diameter (b) of the tumors were determined every three days. The tumor growth curve was analyzed based on the formula $\mathrm{V}=1 / 2 \mathrm{ab}^{2}$. After 3 weeks, the mice were sacrificed and tumor tissues were isolated from them. The tumor size was calculated, and tumor tissues were preserved in liquid nitrogen for later use.

\section{Cell counting kit 8 (CCK8) assay}

Cell lines (HEPG2, HepG2, Bet-7402 and smmc7721) were separately seeded into four 96-well plates at a density of $10^{4} /$ well, and added with $100 \mu \mathrm{L}$ medium into each well. Five duplicate wells and five blank wells were set for each group. The plates were cultured in an incubator containing $5 \% \mathrm{CO}_{2}$ at $37^{\circ} \mathrm{C}$. At 0 th $\mathrm{h}, 24$ th $\mathrm{h}$, 48 th $\mathrm{h}$, and 96 th $\mathrm{h}$ of culture, the CCK8 kit $(10 \mu \mathrm{L})$ was added into each well. After $2 \mathrm{~h}$ of incubation, the optical density (OD) was detected by a microplate reader at the wavelength of $450 \mathrm{~nm}$, and the proliferation curve was drawn. The actual OD value of each well $=$ OD value of the test well - average OD value of the blank well.

\section{Terminal deoxynucleotidyl transferase dUTP nick end labeling (TUNEL) assay}

Cells were added into 96-well plates (100 $\mu \mathrm{L} / w e l l ;$ $2 \times 10^{4}$ cells/well) and incubated overnight, followed by cell transfection. Then, cells were cultured in an incubator containing $5 \% \mathrm{CO}_{2}$ at $37^{\circ} \mathrm{C}$ for $48 \mathrm{~h}$. The medium was discarded and cells were fixed with $4 \%$ paraformaldehyde. The cells were incubated at room temperature for 30 min and washed with PBS. After the addition of $0.3 \%$ $\mathrm{H}_{2} \mathrm{O}_{2}$-methanol solution, cells were incubated at room temperature for another $30 \mathrm{~min}$. After PBS washing, permeabilization solution ( $0.1 \%$ Triton.X-100 dissolved in $0.1 \%$ sodium citrate solution) was added into plates for a 2-min incubation in an ice-bath, followed by PBS washing. With the addition of $50 \mu \mathrm{L}$ TUNEL reagent, the cells were cultured in a humidified incubator at $37^{\circ} \mathrm{C}$ for $60 \mathrm{~min}$. After three PBS washes, the cell were added with $50 \mu \mathrm{L}$ of 4', 6-diamidino-2-phenylindole (DAPI), followed by incubation at $37^{\circ} \mathrm{C}$ in the dark and another three PBS washes. Cells were observed under a fluorescence microscope and images were captured.

\section{Flow cytometry}

Cells were seeded into 6-well plates at a density of $1 \times 10^{6} /$ well, and washed twice with PBS $48 \mathrm{~h}$ after transfection. Then, cells were digested with $0.25 \%$ ethylenediamine tetraacetic acid (EDTA)-free trypsin. The cells were collected in centrifuge tubes and centrifuged at $1000 \mathrm{rpm}$ for $5 \mathrm{~min}$. The medium was discarded and cells were resuspended in pre-cooled PBS. Next, cells were fixed using $70 \%$ ethanol and placed at $4{ }^{\circ} \mathrm{C}$ overnight. After the cells were centrifuged at $2000 \mathrm{rpm}$ for $5 \mathrm{~min}$ and washed twice with precooled PBS, $500 \mathrm{~mL} \mathrm{PI/Rnase} \mathrm{was}$ added into cells. The mixture was maintained in the dark for $45 \mathrm{~min}$ and transferred into flow tubes to detect the cell cycle distribution.

\section{Quantitative real-time polymerase chain reaction (qRT-PCR)}

HCC tissues and adjacent normal tissues were added with saline solution and homogenized. At the same time, transfected cells from all groups were collected. Total RNA was extracted from the cells and tissues using Trizol method. The purity and concentration of RNA were determinated by ultraviolet spectrophotometry. The RNA integrity was assessed by agarose gel electrophoresis. Primers for miR-126, EGFL7, ERK, Fas/FasL (Fas ligand), Bcl-2 (B cell leukemia/lymphoma-2), and Caspase-3 were designed and synthesized by Shanghai Sangon Biological Engineering Technology \& Services Co., Ltd. (Shanghai, China) (Table 5). Total RNA was used to synthesize cDNA by reverse transcription with the PrimescriptTM RT reagent Kit (Takara Biotechnology Ltd., Dalian, China) with a reaction system volume of 10 $\mu \mathrm{L}$. Reaction conditions of reverse transcription: $16^{\circ} \mathrm{C}$ for $30 \mathrm{~min}, 42^{\circ} \mathrm{C}$ for $30 \mathrm{~min}$, and $85^{\circ} \mathrm{C}$ for $10 \mathrm{~min}$. qRTPCR was performed using SYBR ${ }^{\circledR}$ premix Ex Taq TM Real-time PCR Kit (Takara Biotechnology Ltd., Dalian, China). The reaction conditions of PCR were as follows: $95^{\circ} \mathrm{C}$ pre-denaturation for $2 \mathrm{~min}$ followed by 40 cycles of $95^{\circ} \mathrm{C}$ denaturation for $5 \mathrm{~s}, 60^{\circ} \mathrm{C}$ annealing for $4 \mathrm{~s}$, and $72^{\circ} \mathrm{C}$ extension for $30 \mathrm{~s}$. The OpticonMonitor 3 software (Bio-Rad Laboratories, Inc., Hercules, CA, USA) was applied to analyze miR-126 expression and expressions 
Table 5: Primer sequences for quantitative real-time polymerase chain reaction

\begin{tabular}{cl}
\hline Gene & \multicolumn{1}{c}{ Sequence } \\
miR-126 & F: 5'-ACACTCCAGCTGGGTCGTACCGTGAGTAAT-3' \\
& R: 5'- TGGTGTCGTGGAGTCG-3' \\
FGFL7 & F: 5'-CAACCCGACAGGAGTGGACAGT-3' \\
& R: 5'-TCACGAGTCTTTCTTGCAGGAGC-3' \\
FRK & F: 5'-GGCACCAACCATTGAGCAGA-3' \\
& R: 5'-GATCATTGCTGAGGTGCTGTGTC-3' \\
Fas & F: 5'-GCATCTGGACCCTCCTACCTCTG-3' \\
& R: 5'-GACAAAGCCACCCCAAGTTAGA-3' \\
FasL & F: 5'-TTCTGGTTGCCTTGGTAGGATTG-3' \\
& R: 5'-ACCTTGAGTTGGACTTGCCTGTT-3 \\
Faspase-3 & F: 5'-TACCACGCCACCACCGGCCCA-3' \\
& R: 5'-GGCATTTTGGCTGTCGTCAGGGAA-3' \\
Fcl-2 & R: 5'-ATGTGTGTGGAGAGCGTCAA-3' \\
& F: 5'-AGAGTTCCACAAAGGCATCC-3' \\
GAPDH & R: 5'-AGGGGCCATCCACAGTCTTC-3'
\end{tabular}

Note: miR-126, microRNA-126; F, forward; R, reverse.

of EGFL7 and ERK mRNAs in HCC tissues and adjacent normal tissues as well as the miR-126 expression and expressions of EGFL7, ERK, Fas/FasL, Bcl-2, and Caspase-3 mRNAs in the transfected cells. GAPDH was used as an internal control, and the relative quantitative method was applied to calculate the relative mRNA copy number (measured in triplicate). $2^{-\Delta \Delta C t}$ was used to express the ratio of target mRNA expression relative to the GAPDH mRNA expression.

\section{Western blotting}

Tissue proteins were extracted from $\mathrm{HCC}$ and adjacent normal tissues of patients and tumor tissues in nude mice after lysis. Meanwhile, the total cell protein was extracted from transfected cells. The loading buffer was mixed with $20 \mu \mathrm{g}$ of cell protein or $50 \mu \mathrm{g}$ of tissue protein, and proteins were separated by sodium dodecyl sulfate-polyacrylamide gel electrophoresis (SDSPAGE). These separated proteins were transferred onto a nitrocellulose membrane filter by electrotransfer, and blocked with 5\% skimmed milk in PBS at room temperature for $1 \mathrm{~h}$. After that, the filter containing protein samples was incubated with antibodies against EGFL7, ERK, P-ERK (phosphorylated ERK), Fas/FasL, Bcl-2, Caspase-3, VEGF (vascular endothelial growth factor), and CD31 at $4^{\circ} \mathrm{C}$ overnight. Subsequently, the filter was washed with PBS three times and incubated with horseradish peroxidase (HRP)-conjugated second antibody at room temperature for $1 \mathrm{~h}$. After three PBS washes, protein samples were developed by the enhanced chemiluminescence method. Images of protein bands were captured by Gel imaging system (Bio-Rad Laboratories, Inc., Hercules, CA, USA). The gray-scale value of protein bands was analyzed with $\beta$-actin as the internal reference. The ratio of gray-scale values between the target protein band and the internal reference band was calculated as the relative protein expression.

\section{Determination of tumor angiogenesis}

The tumor-transplanted nude mice were intravenously injected with 1\% Evans Blue. Later, the mice were sacrificed and tumor tissues were isolated from them. The number of vessels increased in the direction of tumors was counted under dissecting microscope. The experiment was conducted with modified method on the basis of the investigation of Kreisle and Ershler [36] .

\section{Dual-luciferase reporter gene assay}

The targeting gene (EGFL7) of miR-126 was predicted using microRNA.org (http://www.microrna. org) and verified by dual-luciferase reporter gene assay. The luciferase activity (Firefly luciferase and Renilla luciferase) was detected according to the manufacturer's protocol (Promega Corp, Madison, Wisconsin, USA). The medium in the 96-well plate was removed and cells in the medium was lightly washed with $100 \mu \mathrm{L}$ PBS. After the addition of $100 \mu \mathrm{L}$ passive lysis buffer (PLB) into each well, cell lysis buffer was collected after gently shaking at room temperature. The cell lysis buffer $(20 \mu \mathrm{L})$ was mixed with luciferase detection agent II $(100 \mu \mathrm{L})$, after which the Firefly luciferase activity was obtained using 
a chemiluminescence detector. Subsequently, the mixture was added with $100 \mu \mathrm{L}$ of $1 \times$ Stop \& Glo Reagent to detect Renilla luciferase activity. Reporter gene expression was expressed as the ratio of Firefly luciferase activity to Renilla luciferase activity.

\section{Follow-up}

The clinical data and follow-up information of all patients were collected. The prognostic information of patients was collected through referral, re-admission records and regular telephone interviews and other ways. The follow-up was ended up in March 2016.

\section{Statistical analysis}

All data were analyzed using SPSS 21.0 statistical software (SPSS, Chicago, IL, USA). Measurement data are expressed as $\overline{\mathrm{x}} \pm \mathrm{s}$. Comparisons of measurement data between two groups were conducted using $t$ test and these among multiple groups were tested by the one-way analysis of variance (ANOVA). Comparisons of enumeration data among groups were performed using the $\chi^{2}$ test. Univariate analysis was used to analyze the correlation between clinicopathological characteristics and the prognosis of HCC patients. And the correlation analysis of protein expression was analyzed by Pearson correlation analysis. $P<0.05$ was considered to indicate statistical significance.

\section{ACKNOWLEDGMENTS AND FUNDING}

This work was supported by the National Natural Science Foundation of China (NSFC; Grant No.:81472268/ H1617). We would like to express our sincere appreciation to the reviewers for their helpful comments on this article.

\section{CONFLICTS OF INTEREST}

The authors declare that they have no conflict of interests regarding the publication of this paper.

\section{REFERENCES}

1. Forner A, Llovet JM, Bruix J. Hepatocellular carcinoma. Lancet. 2012; 379:1245-55.

2. Huang, J. Current progress in epigenetic research for hepatocarcinomagenesis. Sci China C Life Sci. 2009; 52:31-42.

3. Chen PJ, Furuse J, Han KH, Hsu C, Lim HY, Moon H, Qin S, Ye SL, Yeoh EM, Yeo W. Issues and controversies of hepatocellular carcinoma-targeted therapy clinical trials in Asia: experts' opinion. Liver Int. 2010; 30:1427-38.

4. Chen Y, Liu Q, Wu M, Li M, Ding H, Shan X, Liu J, Tao T, Ni R, Chen X. GAB2 promotes cell proliferation by activating the ERK signaling pathway in hepatocellular carcinoma. Tumour Biol. 2016;
5. Farazi TA, Hoell JI, Morozov P, Tuschl T. MicroRNAs in human cancer. Adv Exp Med Biol. 2013; 774:1-20.

6. Zhang JG, Shi Y, Hong DF, Song M, Huang D, Wang CY, Zhao G. MiR-148b suppresses cell proliferation and invasion in hepatocellular carcinoma by targeting WNT1/ beta-catenin pathway. Sci Rep. 2015; 5:8087.

7. Zheng B, Liang L, Wang C, Huang S, Cao X, Zha R, Liu L, Jia D, Tian Q, Wu J, Ye Y, Wang Q, Long Z, et al. MicroRNA-148a suppresses tumor cell invasion and metastasis by downregulating ROCK1 in gastric cancer. Clin Cancer Res. 2011; 17:7574-83.

8. Fang JH, Zhou HC, Zeng C, Yang J, Liu Y, Huang X, Zhang JP, Guan XY, Zhuang SM. MicroRNA-29b suppresses tumor angiogenesis, invasion, and metastasis by regulating matrix metalloproteinase 2 expression. Hepatology. 2011; 54:1729-40.

9. Garzon R, Calin GA, Croce CM. MicroRNAs in Cancer. Annu Rev Med. 2009; 60:167-79.

10. Jiang J, Zhang Y, Guo Y, Yu C, Chen M, Li Z, Tian S, Sun C. MicroRNA-3127 promotes cell proliferation and tumorigenicity in hepatocellular carcinoma by disrupting of PI3K/AKT negative regulation. Oncotarget. 2015; 6:6359-72. doi: 10.18632/oncotarget.3438.

11. Ebrahimi F, Gopalan V, Smith RA, Lam AK. miR-126 in human cancers: clinical roles and current perspectives. Exp Mol Pathol. 2014; 96:98-107.

12. Wang S, Wang X, Guo Q, Wang G, Han X, Li X, Shi ZW, He W. MicroRNA-126 Overexpression Inhibits Proliferation and Invasion in Osteosarcoma Cells. Technol Cancer Res Treat. 2016; 15: NP49-59.

13. Guo C, Sah JF, Beard L, Willson JK, Markowitz SD, Guda K. The noncoding RNA, miR-126, suppresses the growth of neoplastic cells by targeting phosphatidylinositol 3-kinase signaling and is frequently lost in colon cancers. Genes Chromosomes Cancer. 2008; 47:939-46.

14. Zhao C, Li Y, Zhang M, Yang Y, Chang L. miR-126 inhibits cell proliferation and induces cell apoptosis of hepatocellular carcinoma cells partially by targeting Sox2. Hum Cell. 2015; 28:91-9.

15. Saito Y, Friedman JM, Chihara Y, Egger G, Chuang JC, Liang G. Epigenetic therapy upregulates the tumor suppressor microRNA-126 and its host gene EGFL7 in human cancer cells. Biochem Biophys Res Commun. 2009; 379:726-31.

16. Fernandez M, Semela D, Bruix J, Colle I, Pinzani M, Bosch J. Angiogenesis in liver disease. J Hepatol. 2009; 50:604-20.

17. Zhu AX, Duda DG, Sahani DV, Jain RK. HCC and angiogenesis: possible targets and future directions. Nat Rev Clin Oncol. 2011; 8:292-301.

18. Coulon S, Heindryckx F, Geerts A, C. Van Steenkiste, Colle I, Van H.Vlierberghe. Angiogenesis in chronic liver disease and its complications. Liver Int. 2011; 31:146-62.

19. Aoki T, Kokudo N, Matsuyama Y, Izumi N, Ichida T, Kudo M, Ku Y, Sakamoto M, Nakashima O, Matsui O, Makuuchi M, Liver J. Cancer Study Group of. Prognostic 
impact of spontaneous tumor rupture in patients with hepatocellular carcinoma: an analysis of 1160 cases from a nationwide survey. Ann Surg. 2014; 259:532-42.

20. Kuhnert F, Mancuso MR, Hampton J, Stankunas K, Asano T, Chen CZ, Kuo CJ. Attribution of vascular phenotypes of the murine Egfl7 locus to the microRNA miR-126. Development. 2008; 135:3989-93.

21. Sasahira T, Kurihara M, Bhawal UK, Ueda N, Shimomoto T, Yamamoto K, Kirita T, Kuniyasu H. Downregulation of miR-126 induces angiogenesis and lymphangiogenesis by activation of VEGF-A in oral cancer. Br J Cancer. 2012; 107:700-6.

22. Wong QW, Lung RW, Law PT, Lai PB, Chan KY, To KF, Wong N. MicroRNA-223 is commonly repressed in hepatocellular carcinoma and potentiates expression of Stathmin1. Gastroenterology. 2008; 135:257-69.

23. Liu XJ, Wang B, Jiang WG, Li YJ, Liu JB, Zhang M. Multivariate analysis of molecular markers in peripheral blood associated with recurrence and metastasis of hepatocellular carcinoma. Genet Mol Res. 2015; 14:1502-7.

24. Li Y, Li Y, Ge P, Ma C. MiR-126 Regulates the ERK Pathway via Targeting KRAS to Inhibit the Glioma Cell Proliferation and Invasion. Mol Neurobiol. 2016;

25. Sun Y, Bai Y, Zhang F, Wang Y, Guo Y, Guo L. miR-126 inhibits non-small cell lung cancer cells proliferation by targeting EGFL7. Biochem Biophys Res Commun. 2010; 391:1483-9.

26. Hu MH, Ma CY, Wang XM, Ye CD, Zhang GX, Chen L, Wang JG. MicroRNA-126 inhibits tumor proliferation and angiogenesis of hepatocellular carcinoma by down-regulating EGFL7 expression. Oncotarget. 2016; 7:66922-34. doi: 10.18632/oncotarget.11877.

27. Zheng ZZ, Ming YL, Chen LH, Zheng GH, Liu SS, Chen QX. Compound K-induced apoptosis of human hepatocellular carcinoma MHCC97-H cells in vitro. Oncol Rep. 2014; 32:325-31.

28. Xu WH, Zhang JB, Dang Z, Li X, Zhou T, Liu J, Wang DS, Song WJ, Dou KF. Long non-coding RNA URHC regulates cell proliferation and apoptosis via ZAK through the ERK/ MAPK signaling pathway in hepatocellular carcinoma. Int J Biol Sci. 2014; 10:664-76.

29. Lai JP, Sandhu DS, Yu C, Moser CD, Hu C, Shire AM, Aderca I, Murphy LM, Adjei AA, Sanderson S, Roberts LR. Sulfatase 2 protects hepatocellular carcinoma cells against apoptosis induced by the PI3K inhibitor LY294002 and ERK and JNK kinase inhibitors. Liver Int. 2010; 30:1522-8.

30. Wei G, Wang M, Hyslop T, Wang Z, Carr BI. Vitamin K enhancement of sorafenib-mediated HCC cell growth inhibition in vitro and in vivo. Int $\mathrm{J}$ Cancer. 2010; 127:2949-58.

31. Campagnolo L, Telesca C, Massimiani M, Stuhlmann H, Angelico M, Lenci I, Manzia TM, Tariciotti L, Lehmann G, Baiocchi L. Different expression of VEGF and EGFL7 in human hepatocellular carcinoma. Dig Liver Dis. 2016; 48:76-80.

32. Wu F, Yang LY, Li YF, Ou DP, Chen DP, Fan C. Novel role for epidermal growth factor-like domain 7 in metastasis of human hepatocellular carcinoma. Hepatology. 2009; 50:1839-50.

33. Yang F, Li J, Zhu J, Wang D, Chen S, Bai X. Hydroxysafflor yellow A inhibits angiogenesis of hepatocellular carcinoma via blocking ERK/MAPK and NF-kappaB signaling pathway in H22 tumor-bearing mice. Eur J Pharmacol. 2015; 754:105-14.

34. Kim SJ, Kim JS, Papadopoulos J, Wook Kim S, Maya M, Zhang F, He J, Fan D, Langley R, Fidler IJ. Circulating monocytes expressing CD31: implications for acute and chronic angiogenesis. Am J Pathol. 2009; 174:1972-80.

35. de Giorgio A, Castellano L, Krell J, Stebbing J. Crosstalkinduced loss of mir-126 promotes angiogenesis. Oncogene. 2014; 33:3634-3635.

36. Kreisle RA, Ershler WB. Investigation of tumor angiogenesis in an id mouse model: role of host-tumor interactions. J Natl Cancer Inst. 1988; 80:849-54. 